\title{
37\% Phosphoric Acid Induced Stronger Matrix Metalloproteinase-8 Expression of the Dental Pulp than 19\% Ethylene Diamine Tetraacetic Acid
}

Nadie Fatimatuzzahro ${ }^{1^{*}}$, Tetiana Haniastuti ${ }^{2}$, Juni Handajani ${ }^{2}$

${ }^{1}$ Biomedic Department, Dentistry Faculty, Jember University, Jember, Indonesia

${ }^{2}$ Oral Biology Department, Dentistry Faculty, Gadjah Mada University, Yogyakarta, Indonesia

\begin{abstract}
Etching agents such as ethylene diamine tetraacetic acid (EDTA) and phosphoric acid which are widely used in adhesive restoration system aimed to increase for retention of restorative materials, may act a chemical irritant that induce inflammation of dental pulp. Inflammation is a body response against irritant and infectious agents. Matrix metalloproteinase- 8 , the major collagenolytic enzyme, degrades collagen type 1 . This enzyme is expressed in low level in normal condition, however, the expression will increase during inflammation. The purpose of the present research was to study the effect of 19\% EDTA and 37\% phosphoric acid application as an etching agents on the MMP-8 expression of dental pulp. Forty-five male Sprague Dawley rats were divided into 3 groups. Cavity preparation was made on the occlusal surface of maxillary first molar using a round diamond bur. 19\% EDTA, $37 \%$ phosphoric acid, and distilled water were applied on the surface of the cavity of the teeth in group I, II, and III subsequently. The cavity then filed by glass ionomer cements. The rats were sacrified at 1, 3, 5, 7, and 14 days after the treatment ( $\mathrm{n}=3$ for each day). The specimens were then processed histologically. Immunohistochemical (IHC) analysis was performed using rabbit anti rat MMP-8 polyclonal antibody to examine MMP-8 expression and HE (Hematoxylen Eosin) staining to observe the number of macrophages. The results showed $37 \%$ phosphoric acid application induced stronger expression of MMP-8 and higher number of macrophages than 19\% EDTA. The strongest expression of MMP-8 seems on 5 days after the treatment where the highest number of macrophages were also found.
\end{abstract}

Keywords: dental pulp, EDTA, inflammation, MMP-8, phosporic acid

\section{INTRODUCTION}

Adhesive restorations are common restorative method used in clinical practice. This method has some advantages, i.e. good aesthetic and do not require much tooth substance disposal [1]. Application of etching agent in adhesive system restoration is needed to improve the quality of the adhesion between restorative material and tooth. Application of the etching agent is aimed to eliminate smear layer and inorganic components of the tooth; hence, generate microporosity that will be filled by the adhesive [2]. One of the most widely used etching agent in adhesive restoration systems is $32-37 \%$ phosphoric acid. The agent actives at low $\mathrm{pH}$ [3]. Torii et al., showed that phosphoric acid etching reduced the adhesion strength of composite

\footnotetext{
${ }^{*}$ Corresponding author:

Nadie Fatimatuzzahro

Biomedic Department, Dentistry Faculty, Jember University

Jl. Kalimantan 37 Jember, Indonesia 68121

Email: nadiefatima@gmail.com
}

resin to dentin [4]. Okuda et al., revealed that excessive demineralization occurred after phosphoric acid application, thus, may cause adhesion failure due to insufficient infiltration of resin monomers [5].

Ethylene diamine tetraacetic acid is a chelating agent that has ability to remove the smear layer effectively [6]. The application of 0.5 M EDTA (equivalent to $19 \%$ EDTA) for 30 seconds minimize microleakage at composites and dentin interface [7]. In comparison with $37 \%$ phosphoric acid, this agent increases more adhesion strength [8].

Matrix metalloproteinase (MMP) is a class of endopeptidase enzymes capable of degrading almost all components of the extracellular matrix. Sulkala et al., showed that MMP-8 was the major collagenase in human dentin [9]. Matrix metalloproteinase- 8 using collagen type I as a substrate [10]. Matrix metalloproteinase- 8 is expressed by neutrophils, chondrocytes cells, fibroblasts, endothelial, odontoblas $[9,10]$ and macrophages [11]. MMP-8 is expressed at low levels in 
normal conditions; the expression is upregulated during inflammation [11].

The dentin-pulp complex reacts to all stimuli, such as caries, trauma, and restorative procedures [12]. Various substances used in restorative procedures such as phenol, eugenol, and dentin cleanser agents may induce pulp inflammation [13]. The purpose of the present research was to study the effect of $19 \%$ EDTA and $37 \%$ phosphoric acid application as an etching agents on the MMP-8 expression of the dental pulp.

\section{MATERIALS AND METHODS}

\section{Ethylene Diamine Tetraacetic Acid solution prepara- tion}

$19 \%$ ethylene diamine tetraacetic acid was made by dissolving 19 grams of EDTA powder (molecular weight of $372.24 \mathrm{~g} / \mathrm{mol}$ ) in $100 \mathrm{cc}$ distilled water using a magnetic stirrer. $\mathrm{pH}$ was adjusted to 7.4.

\section{Experimental Animals}

The protocol applied for this animal experiment was approved by the ethics committee of the Faculty of Dentistry, Gadjah Mada University, Yogyakarta. Fortyfive, four-month-old male Sprague Dawley rats with an average body weight of 250-300 g, healthy and had no abnormalities were divided into 3 groups. Cavity preparation was made on the occlusal surface of maxillary first molar. 19\% EDTA was applied to the cavity in group I for 30 seconds and $37 \%$ phosphoric acid gel (Dentamerica, USA) in group II for 20 seconds, then rinse with distilled water for 30 seconds [14]. The cavity just rinsed with distilled water for 30 seconds in group III. The cavity then were dried and filled by glass ionomer cement Fuji IX (GC, Japan). The rats were sacrified at $1,3,5,7$, and 14 days after the treatment.

\section{Histological preparations}

The specimens were decalcified using 10\% EDTA, embedded in paraffin, and sectioned serially, then stained with hematoxylin eosin (HE) and immunohistochemistry (IHC). Immunohistochemistry procedure was performed using rabbit anti rat MMP-8 polyclonal antibody (Abcam, USA) to examine MMP-8 expression. The specimens were observed under a microscope with 400x magnification in three different field at the area beneath the cavity. Macrophages were counted and MMP-8 expression was evaluated by scoring the intensity of its brown color.

\section{RESULTS AND DISCUSSION}

Immunohistochemical examination showed brown staining with varying intensity which indicates the expression of MMP-8. More stronger intensity of the brown color, more stronger expression of MMP-8. Brown staining with weak intensity appeared in intact teeth (without treatment) (Figure 1). This suggests that under normal conditions, pulp cells express MMP-8 in the lower levels and secreted into the extracellular matrix.

MMP-8 expression showed in Figure 2. In all specimens 1 day after the application of etching agents, MMP-8 expression was detected in many pulp cells and extracellular matrix in the area beneath the cavity. All samples in the group applied with 19\% EDTA and distiled water showed weak expression of MMP-8, while in the group applied with $37 \%$ phosphoric acid showed moderate intensity. Three days after the treatment, all specimens showed MMP-8 expression with moderate intensity in the extracellular matrix of the coronal pulp with the larger area than day 1. Odontoblasts below the cavity revealed MMP-8 expression stronger than the other areas in the pulp

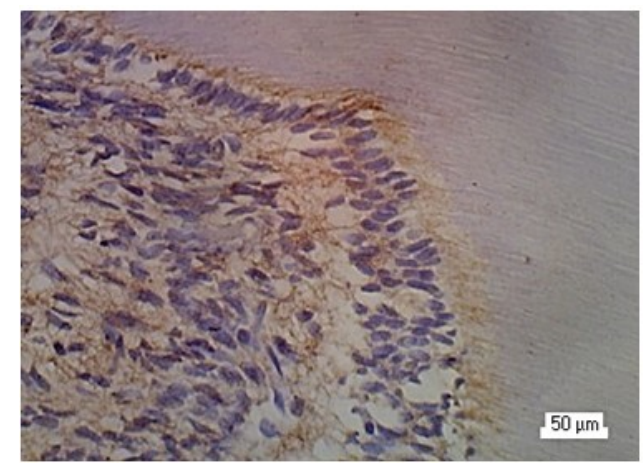

Figure 1. Immunohistochemical staining anti MMP-8 of intact tooth showed weak intensity in the cytoplasm pulp cells and extracellular matrix. 


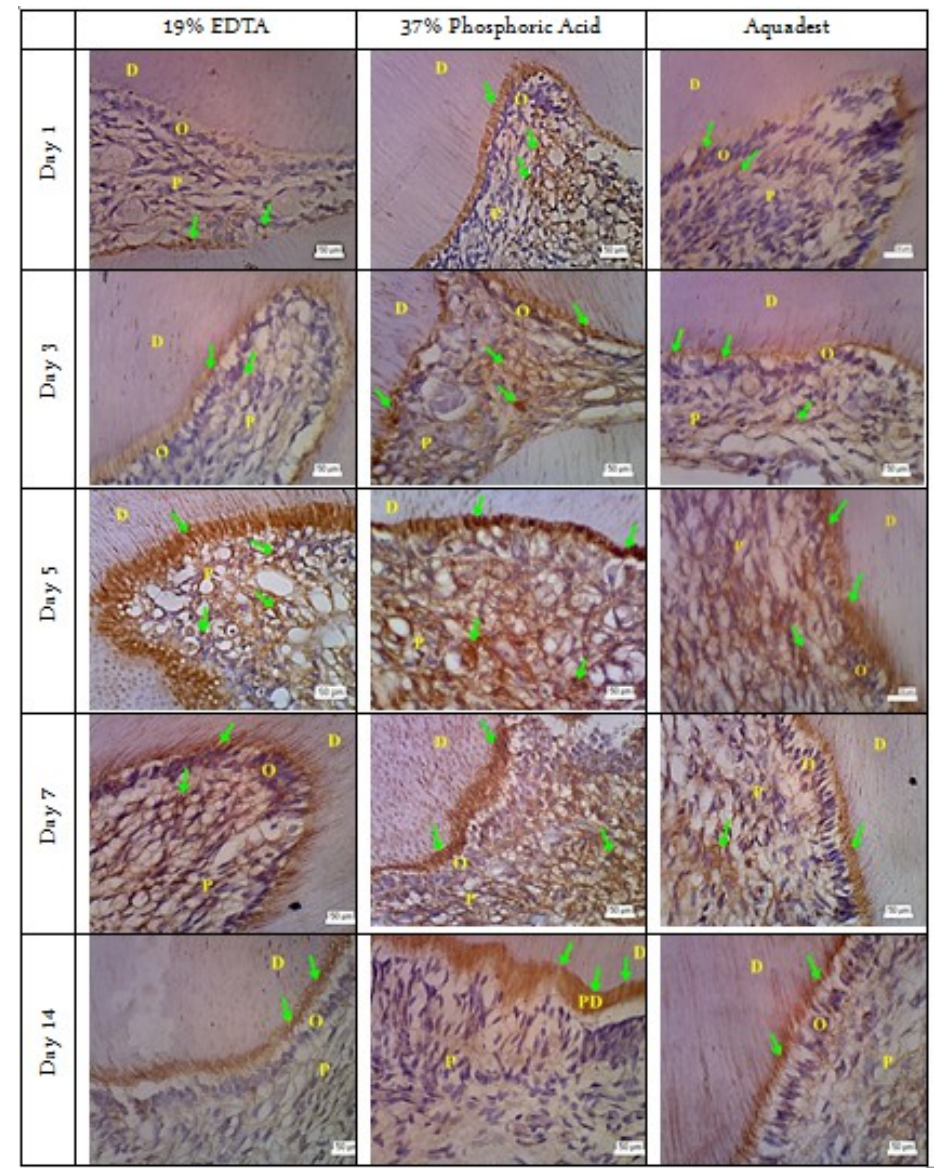

Figure 2. Immunohistochemical features showed brown staining which indicates of MMP 8 expressions. Green dart showed expression of MMP 8 in the cell and matrix. Strong intensity of MMP-8 expressed after application 37\% phosphoric acid compared with EDTA 19\%. D: dentin, O: odontoblasts, P: pulp, PD: predentin.

chamber.

MMP-8 expression with strong intensity was seen in the extracellular matrix of the coronal pulp and predentin area as well in all samples of all groups at 5 days after the treatment. Seven days after the treatment, 2 out of 3 samples in the group applied with $37 \%$ phosphoric acid showed MMP-8 expression with strong intensity, while one sample showed moderate intensity. Expression of MMP-8 appears with moderate intensity was observed in 2 out of 3 samples applied with 19\% EDTA, while the remaining sample showed a strong intensity. However, 14 days after the treatment all groups showed moderate intensity of MMP-8 expression, especially in predentin area.

Macrophages were already observed 1 day after the aplication (Figure 3A). The number of macrophages was then increased 3 days after the treament and reached the highest number 5 days after the treatment.
The number of macrophages were decreased afterwards (Figure 3B).

Two-way ANOVA showed significant differences of the number of macrophages infiltration among the groups $(p<0.05)$, indicating that application of etching agent had significant effect on the number of macrophages infiltration. Tuckey HSD test showed significant differences of the number of macrophages infiltration after application of $37 \%$ phosphoric acid compared to $19 \%$ EDTA $(\mathrm{p}<0.05)$. The result showed that application of $37 \%$ phosphoric acid induced more macrophages infiltration than 19\% EDTA. 

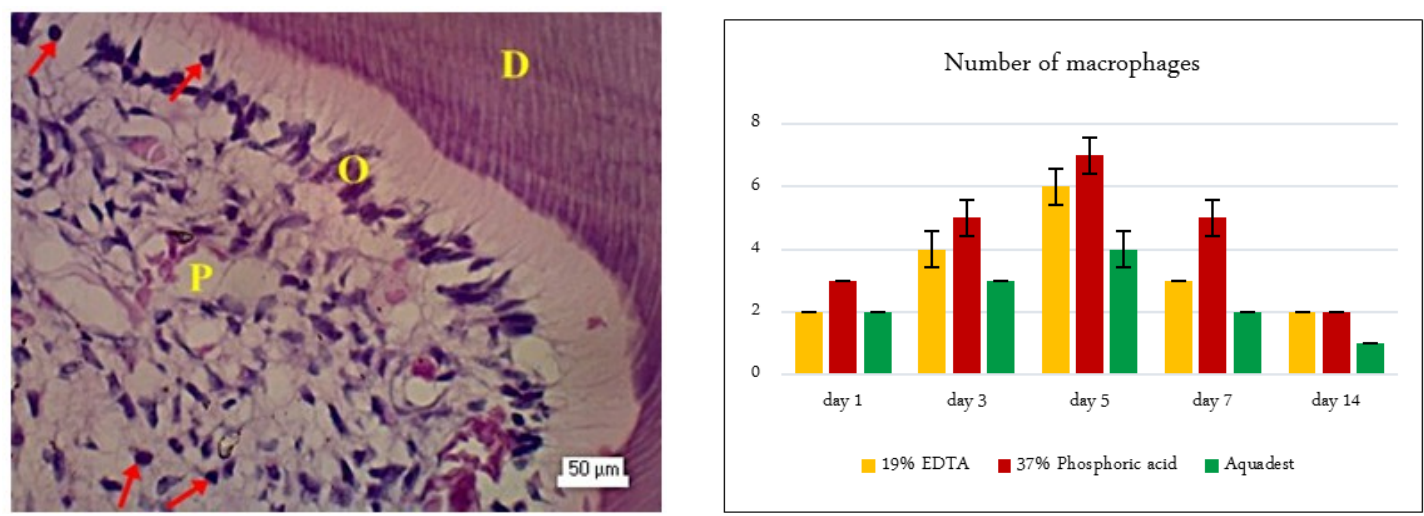

Figure 3. A. Haematoxilin eosin staining of macrophages. An arrow red showed macrophages in pulp. D: dentin, O: odontoblasts, P: pulp, B. Bar graphs showed the highest number of macrophages seen after application $37 \%$ phosphoric acid.

This study showed that application of 37\% phosphoric acid stimulated more pulp inflammation than 19\% EDTA which is characterized by more macrophages infiltration and strongest intensity of MMP-8 expression. This is likely due to the low $\mathrm{pH}$ of $37 \%$ phosphoric acid while 19\% EDTA. When the phosphoric acid applied to the cavity, excessive demineralization might occur and increase dentin permeability resulting in large penetration of etching agent through the dentinal tubules to the pulp [15]. In addition, acid etching with low $\mathrm{pH}$ may cause hypertonic environment. It induced the cell to shrink, and may lead to permanent damage of the odontoblasts and an inflammatory reaction [16].

The present study showed that application of distilled water on the surface of the cavity induced inflammatory cells infiltration in the dental pulp as well. This was probably caused by a cavity preparation. A research conducted by Feng Mei et al., revealed that the friction and heat generated from rotary instruments resulted in increasing expression of nitric oxide (NO) by odontoblasts [17]. Nitric oxide, a free radical, is produced from the nitric oxide synthase (NOS). Free radical causes vasodilation, so that the inflammatory cells migrate from the blood vessels to the tissue [18].

All treatment groups showed stronger MMP-8 expression than normal intact teeth, indicating that the inflammation caused by cavity preparation and the application of etching agent affects the expression of MMP-8. In normal condition, MMP-8 is expressed at low level; the expression is upregulated during inflammation which contribute to tissue damage by degrading the extracellular matrix [19]. Expression of MMP-8 by odontoblasts and pulp fibroblasts was induced by pro inflammatory cytokines such as TNF- $\alpha$ and IL-1, then secreted into the extracellular matrix through the exocytosis process shortly after synthesized [20].

Macrophages play an important role in the immune system to recognize irritants and cellular debris [20], phagocytes and eliminate antigen [18]. The cells were then activated and secreted cytokines such as IL-1 and TNF- $\alpha$ which plays an important role in the inflammatory response [21]. Tumor necrosis factor- $\alpha$ induces endothelium and dendritic cells to produce monocyte chemotactic protein-1 (MCP-1) and stimulate the monocytes out of the blood vessels leading to the area of inflammation. Monocytes will differentiate into macrophages in the pulp tissue. It takes 48-72 hours for monocytes to differentiate into macrophages after migrate to the tissue [20]. Macrophages observed in all groups 1 day after the application; the number of macrophages increased and reached highest 5 days after the application. As the number of macrophages infiltration increased, the expression of MMP-8 was increased as well. Matrix metalloproteinase- 8 is a lysosomal enzyme, stored in intracellular granules, which then secreted into the extracellular matrix by activated neutrophils and macrophages [11].

The expression of MMP-8 decreased until day 14 after treatment and mainly seen in predentin area. Predentin is a zone for the organization of collagen prior to mineralization. Matrix metalloproteinase- 8 was secreted by odontoblasts to the predentin area possibly related to the formation of tertiary dentin. It play a role in degrading collagen matrix allowing for further mineral ions deposition [10]. Matrix metalloproteinase- 
8 play role in collagen matrix damage during the development of caries [22], inflammatory tissue damage in the pulp [23], initiation and organization of dentin matrix before the process mineralization [24] and the formation of tertiary dentin [23]. Degradation of extracellular matrix is a signal for odontoblas to secrete matrix that play a role in the repair of the pulp.

This research used glass ionomer cement as a restorative material to fill the cavity instead of composite resin. Glass ionomer cement induces less irritation to the pulp compare to composite resin [25]. Temporary filling was not used in this study due to its low resistance in the oral cavity [26].

\section{CONCLUSIONS}

In conclusion, $37 \%$ phosphoric acid induced higher number of macrophages and stronger expression of MMP-8 than $19 \%$ EDTA. As the number of macrophages infiltration increased, the expression of MMP-8 was increased as well. The results of this study can provide information that $19 \%$ EDTA as an etching agents is more biocompatible for pulp cells. Increase expression of MMP-8 is leading to degradation of the extracellular matrix, that can affect the composite restoration failure due to the degradation of collagen in the hybrid layer, loss of adhesion and increase the incidence microleakage of restoration.

\section{ACKNOWLEDGEMENT}

We are grateful to thank to Dewi K. Paramita, S.Si.,M.Si.,Ph.D and Sumaryati, A.Md., for their valuable help in conducting this research.

\section{REFERENCES}

1. Walmsley AD, Walsh TF, Lumley PJ, Burke FJT, Shortall AC, Hayes-Hall R, Pretty IA (2007) Restorative Dentistry. Second edition. Elsevier. Philadelphia.

2. Summit JB, Robbins JW, Hilton T, Schwartz R. Fundamentals of Operative Dentistry (2006) A contemporary Approach. Third edition. Quintessence Publishing Co Inc. Illinois.

3. Roberson TM, Harald OH, Edward JS (2006) Sturdevant's Art and Science of Operative Dentistry. Fifth Edition. Mosby Elsevier. St. Louis.

4. Torii Y, Itou K, Nishitani Y, Ishikawa K, dan Suzuki K (2002) Effect of Phosphoric Acid Etching Prior to SelfEtching Primer Application on Adhesion of Resin Composite to Enamel and Dentin. Am. J. Dent. 15(5): 305-308.

5. Okuda M, Pereira PN, Nakajima M, Tagami J, Pashley DH (2002) Long - Term Durability of Resin Dentin Interface: Nanoleakage vs. Microtensile Bond Strength. Op.
Dent. 27(3): 289-296.

6. Cederlund A, Jonsson B, Blomlof J (2001) Shear Strength after Ethylenediaminetetraacetic Acid Conditioning of Dentin. Acta Odontol Scand. 59: 418-422.

7. Shafie F, Memarpour M (2008) Effect of EDTA Conditioning on Mikroleakage of Four Adhesive System in Composite Restorations. J Dent. 5(3): 150-155.

8. Jacques P, Hebling J (2005) Effect of Dentin Conditioners on Mocrotensile bond Strength of a Conventional and a Self-Etching Primer Adhesive System. Dent Mater. 21: 103-109.

9. Sulkala M, Tervahatiala T, Sorsa T, Larmas M, Salo T, Tjaderhane L (2007) Matrix Metalloproteinase-8 (MMP-8) is the Major Collagenase in Human Dentin. Arch Oral Biol. 52: 121-127.

10. Palosaari H, Wahlgren J, Larmas M, Ronka H, Sorsa T, Salo T, Tjaderhane L (2000) The Expression of MMP-8 in Human Odontoblasts and Dental Pulp Cells is DownRegulated by TGF Beta-1. J Dent Res. 79: 77-84.

11. Wahlgren J, Salo T, Teronen O, Luoto H, Sorsa T, Tjaderhane L (2002) Matrix Metalloproteinase-8 (MMP-8) in Pulpal and Periapical Inflammation and Periapical Root Canal Exudates. Int Endod J. 35: 897-904.

12. Sundoro EH (2005) Serba-Serbi Ilmu Konservasi Gigi. Universitas Indonesia Press. Jakarta.

13. Walton R, Torabinejad M (2008) Principles and Practice of Endodontics. Third edition. EGC. Jakarta.

14. Stape, THS, Menezes MS, Barreto BCF, Aguiar FHB, Martins LR, Quagliatto PS (2012) Influence of Matrix Metalloproteinase Synthetic Inhibitors on Dentin Microtensile Bond Strength of Resin Cements. Op. Dent. 37(4): 386-396.

15. Amaral KF, Rogero MM, Fock RA, Borelli P, Gavini G (2007) Cytotoxicity Analysis of EDTA and Citric Acid Applied on Murine Resident Macrophages Culture. Int Endod J. 40: 338-343.

16. Nemeth L, Erman A, Stiblar-Martincic D (2006) Early Odontoblastic Layer Response to Cavity Preparation and Acid Etching in Rats. Folia Biol (Krakow). 54: 23-30.

17. Feng Mei Y, Yamaza T, Atsuta I, Danjo A, Yamashita Y, Kido MA, Goto M, Akamine A, Tanaka T (2007) Sequential Expression of Endothelial Nitric Oxide Synthase, Inducible Nitric Oxide Synthase, and Nitrotyrosine in Odontoblasts and Pulp Cells During Dentin Repair After Tooth Preparation in Rat Molars. Cell Tissue Res. 328: 117-127.

18. Roitt IM (2002) Essential Immunology: Eight edition. Widya Medika. Jakarta.

19. Sorsa T, Tjaderhane L, Salo T (2004) Matrix Metalloproteinases (MMPs) in Oral Diseases. Oral Diseases. 10: 311318. 
20. Hargreaves MK, Goodis HE (2002) Seltzer and Bender's Dental Pulp. Quintessence Publishing Co Inc. Carol Stream.

21. Cooper PR, Takashi Y, Graham LW, Simon S, Imazato S, Smith AJ (2010) Inflammation-Regeneration Interplay in the Dentin-Pulp Complex. J Dent. 38: 687-697.

22. Tjaderhane L, Palosaari H, Sulkala M, Wahlgren J, Salo T (2001) The Expression of Matrix Metalloproteinases (MMPs) in Human Odontoblasts. Proceedings of the International Conference on Dentin/Pulp Complex. Quintessence Publishing Co Ltd. Tokyo.

23. Tjaderhane L, Larjava H, Sorsa T, Uitto VJ, Larmas M, Salo T (1998) The Activation and Function of Host Ma- trix Metalloproteinase in Dentin Matrix Breakdown in Caries Lession. J Dent Res. 77: 1622-1629.

24. Palosaari H, Permington CJ, Larmas M, Edwards DR (2003) Expression Profile of MMPs and Tissue Inhibitors of MMPs in Mature Human Ododntoblast and Pulp Tissue. Eur J Oral Sci. 111: 117-127.

25. Rendjova V, Gjorgoski I, Ristoski T, Apostolska S (2012) In vivo Study of Pulp Reaction to Glass Ionomer Cements and Dentin Adhesives. Sec Biol Med Sci. 1: 265-277.

26. Schmalz G, Arenholt-Bindslev D (2009) Biocompatibility of Dental Materials. Springer. Berlin. 